\title{
Analysis of factors affecting the ecological status of the large water bodies on the basis of monitoring and integrated 3D models
}

\author{
Ireneusz Zbiciński ${ }^{1, *}$, and Aleksandra Ziemińska-Stolarska ${ }^{1}$ \\ ${ }^{1}$ Lodz University of Technology, Faculty of Process and Environmental Engineering, Wolczanska 213 Street, 90-924 Lodz, Poland
}

\begin{abstract}
The paper presents water monitoring methods used to determine and predict the ecological status of large water bodies based on calibrated 3D water quality models. State monitoring system of quality of water was discussed and critically reviewed. Mobile measurements technique to collect vast number of measuring points across the large water body during one day cruise to make maps of pollutants distributions was described. Maps of water quality parameters show dynamic changes of spatial distributions of pollutants both in time and along the length of the lake which proves that one point measurements cannot be representative for the large water body. Critical evaluation of calibration principles and accuracy of the most frequently used water quality models, WASP and GEMSS are presented. On the basis of CFD calculations, close correlation between water quality and hydrodynamics in large water bodies regarding the physicochemical aspects and biological production was proved. Neglecting the effect of hydrodynamic on eutrophication process introduce large element of uncertainty in determination of nutrients flow in the large water bodies. An example of scenarios for improving the ecological potential of dam reservoirs to obtain significant reduction of selected nutrients concentration in the lake is discussed.
\end{abstract}

\section{Introduction}

Declining water quality has become a global problem due to human populations grow, expansion of industrial and agricultural activities and climate change which alter the hydrological and biogenic cycles. Globally, the most prevalent water quality problem is eutrophication, a result of high-nutrient loads, which substantially impairs beneficial uses of water. The main sources of the pollution are emissions to water of sewage and pollutant effluents, which increase load of biogenic and other substances causing e.g. seasonal cyanobacterial blooms.

Anthropogenic activities effecting water quality include also deepening and widening of waterways, the construction of port basins causing disturbance of bottom sediments. Wastewater delivered to water bodies is mainly produced through agricultural activities (natural and artificial fertilization, animal production, leakages from fertilizer containers, manure, plant protection products) and municipalities (lack of sewage system, leakage of septic tanks, runoff of sewage from the streets).

Significant contribution in the eutrophication of waters is caused also by emission from point sources produced by municipal and industrial wastewater treatment plants or discharges from sanitary and storm sewers.

To collect data necessary for any kind of water management decisions, state program of monitoring of quality of water bodies has been developed [1].

Currently, the following types of water quality of monitoring are implemented:

Diagnostic monitoring; carried out every 6 years: covers around 100 indicators: biological and physicochemical, salinity, acidification, biogenic substances, aerobic conditions, particularly harmful substancespriority substances, etc.

Operational monitoring: carried out every 3 years controls biological elements and physico-chemistry of waters. The goal of operational monitoring is to determine the state of the JCWP (Uniform Part of Surface Waters) and to track changes resulting from the action programs dedicated to improve the state of the waters.

Additional requirements are set for recreational areas, including bathing areas and areas sensitive to eutrophication caused by pollution from municipal sources.

Research monitoring is used to determine the effect of accidental pollution on environment or to explain the reason of not achieving the environmental goals attained to given JCWP.

Due to high costs of monitoring, even for a single measuring point (costs of measuring system, installation of the buoy, maintenance), standard measurements are carried out from 3 to 6 years. To use the data from years

Corresponding author: ireneusz.zbicinski@p.lodz.pl 
between the measurements, the Mark Heritage Rule [1] was introduced. "Mark (Factor) heritage rule" says that data collected in previous years can be used to estimate current ecological status of the water body according to the following principles: biological elements can be used on the level of single factor for 6 years for fish species, the other for 3 years. Physico-chemical and hydromorfological elements must be taken from the last year of biological evaluation whereas chemical elements, from the last 6 years.

Question arises how representative are the data collected from single measuring point for the large water body? Can we assume uniform distribution of physicochemical, biological and hydromorfological parameters in large reservoirs?

The question is crucial for accurate description of ecological status of water bodies and correct management decisions regarding current and future actions towards maintenance and improvement of environment quality.

\section{Measurements of water quality parameters}

Problem of quality and quantity of data for correct description of ecological status of large water bodies was considered in the frame of MONSUL project (20152017) devoted to determination of ecological status of Sulejow Reservoir [2]. The ultimate goal of the project was to develop a universal tool for critical and balanced decisions concerning environmental protection and planning related to the environment of the reservoir waters.

In the MONSUL project mobile measurements technique to collect large number of measurements of water quality parameters together with the exact time and location across the entire reservoir during one day cruise was developed. The measurement were made using EXO 2 multi-parameter probe (YSI, USA) with data collection and transmission to provide continuous measurements of the following parameters: water temperature, $\mathrm{pH}$, dissolved oxygen concentration, conductivity, chlorophyll and blue green algae (BGA) concentration and ammonium ion concentration.

Traditional, stationary measurements were also carried out using the buoy equipped with the EXO 2 multi-parameter probe and a meteorological station measuring air temperature, humidity, wind speed and direction, atmospheric pressure and insolation. For the purpose of measurements in motion, a special extension boom was installed on the motorboat to attach the EXO2 probe. The construction of the boom enabled to control probe immersion depth and allow access to the probe for observation and periodic cleaning. After tests of motorboat measurements and comparing results from mobile and stationary measurements in the same location point (reference value), optimal speed of the boat (around $5 \mathrm{~km} / \mathrm{h}$ ) at which the results of both measurements matched with good accuracy was set. A typical route for one day motorboat measurements tracked with a GPS system is shown in Fig. 1.
Elaborated methodology of mobile measurements enabled to collect around 700 during one cruise.

Data collected during mobile measurements, after transformation into a spatial datum located on the surface of the reservoir (GIS processing systems) allow to make precise maps of water quality parameters in the water body.

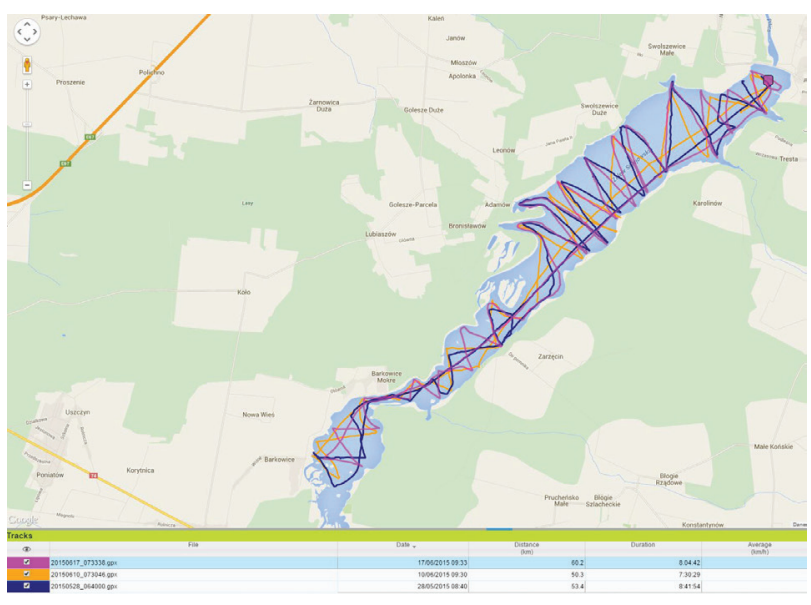

Fig. 1. An example of the route of the motorboat for one day mobile measurements determined by a GPS system.

A series of mobile measurements of the water quality parameters carried out in June/September 2015 shown dramatic changes of spatial distributions of pollutants both in time and along the length of the lake, Fig. 2 and 3.

Spatial distributions of chlorophyll and blue green algae (BGA) concentration between June and September 2015 are shown in Figs. 2 and 3.

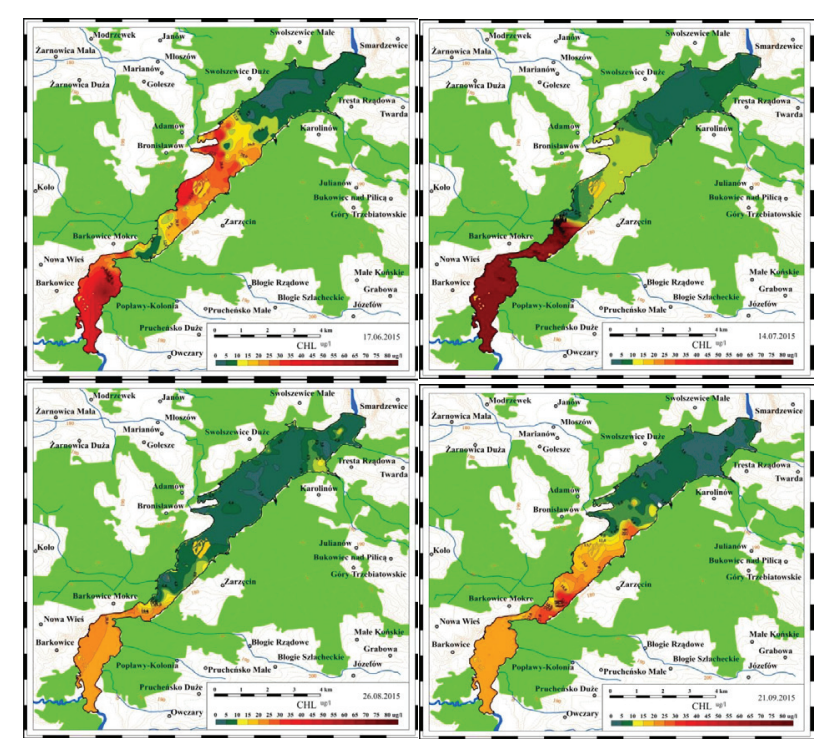

Fig. 2. Spatial distribution of chlorophyll concentration in June/September 2015.

Analysis of Figs. 2 and 3 proves that one point measurements cannot be representative for the entire water body.

Differences in concentrations of chlorophyll and blue green algae are even tenfold in the same measuring day, which confirms that not only quality but also quantity of 
the data are important for all actions to improve of ecological status of large water body [3].

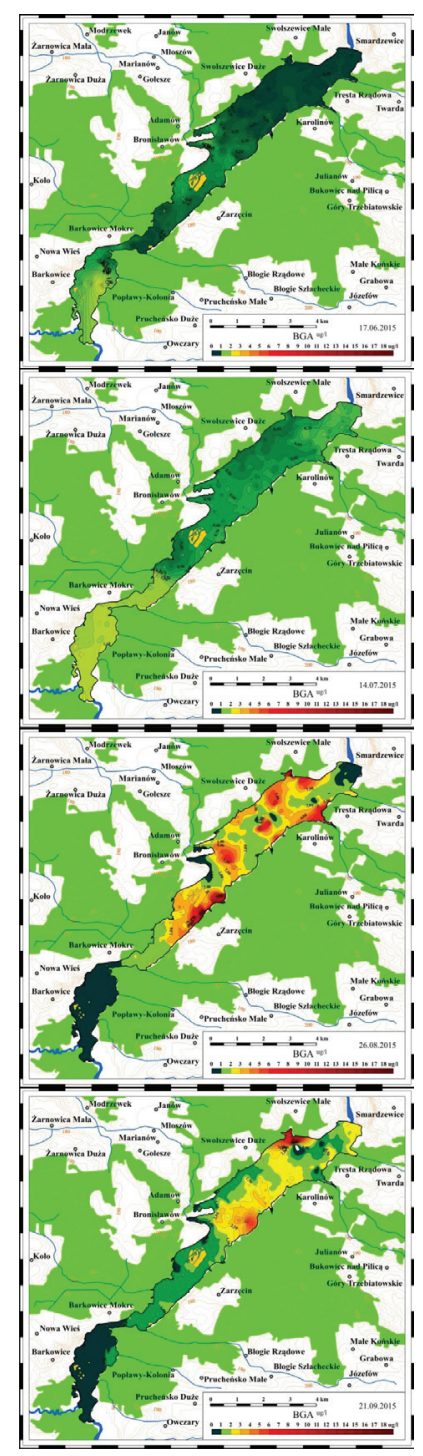

Fig. 3. Spatial distribution of blue green algae (BGA) concentration June/ September 2015.

To support water management decisions and study relationships in the ecosystem surface water quality models can be used.

\section{Water quality models}

The objective of water quality modeling is to study the characteristics of the spatial and temporal distribution of water quality variables under different conditions and various external factors. There is a big diversity of water quality models, from a single factor of water quality indicators to multifactor, from steadystate models to dynamic, from point source models to the coupling models of point and nonpoint sources, and from zero-dimensional (input-output models) to one-, twoand three-dimensional models $[4,5]$.

Significant efforts were expended in developing mathematical models to predict eutrophic status of the natural and man-made water bodies, as a function of nutrient inputs $[6,7,8,9]$. With understanding of relationship between the eutrophication processes and hydrodynamics, as well as with more advanced computing capability, multidimensional models of lakes and reservoir have been developed to study water quality problems $[10,11,12,13]$.

Cao and Zhang [14] classified of water-quality models based on water body types, model-establishing methods, water quality coefficients, components, model property, spatial dimension, and reaction kinetics. Selected water quality models with a brief description are presented below:

Streeter-Phelps models, 1-D steady-state models focus on oxygen balance and one-order decay of BOD [15].

QUAL, 1-D river and stream water quality models

suitable for dendritic river and non-point source pollution including steady-state or dynamic models [14].

Water Analysis Simulation Program, WASP, Dynamic compartment-modeling program for aquatic systems, including water column and the underlying benthos which allows to investigate 1, 2, and 3-D systems, and a variety of pollutant types. Can be linked with hydrodynamic and sediment transport models that can provide flows, depths velocities, temperature, salinity and sediment fluxes $[16,17]$.

MOHID, 3-D water modeling system which integrates modules for the simulation of hydrodynamics, water quality and sediment processes. The integration of MOHID different tools, (MOHID Water, MOHID Land and MOHID Soil) can be used to study the water cycle in an integrated approach [18].

Generalized Environmental Modeling System for Surface Waters, GEMSS, 3-D hydrodynamic and transport models embedded in a geographic information and environmental data system (GIS). Compute timevarying velocities, water surface elevations, and water quality constituent concentrations in rivers, lakes, reservoirs, estuaries, and coastal water bodies [19].

MIKE, A finite-difference model in an orthogonal grid system for free surface flows. Includes modeling components for advection-diffusion, water quality, heat exchange with the atmosphere, heavy metals, eutrophication, flooding and drying of intertidal areas, and sediment processes. The model can simulate the fate and transport of conservative or linearly decaying constituents, including: nutrient cycling; dissolved oxygen levels; exchange of metals between the bed sediments and the water column; and sediment transport, deposition, and entrainment [20].

The most frequently used models of water quality, with vast number of practical applications are WASP and GEMSS.

Critical evaluation of principles and accuracy of simulations for both models is presented below. 


\subsection{WASP}

The Water Quality Analysis Simulation Program, WASP, is a general dynamic mass balance framework for modeling contaminant fate and transport in surface waters. To date WASP has been employed in over one hundred modeling applications that have included rivers, lakes, estuaries and ocean environments [16,21].

WASP Transport Options: A body of water is represented in WASP as a series of discrete computational elements or segments. Environmental properties and chemical concentrations may vary spatially among the segments. Each variable is advected and dispersed among water segments, and exchanged with surficial benthic segments by diffusive mixing.

WASP Toxicant Modules: The primary WASP toxicant code, TOXI, is combined with separate databases to support four modules-simple toxicant, nonionizing toxicants, organic toxicants, and mercury.

WASP Eutrophication Module: The WASP eutrophication code, EUTRO, EUTRO output reports state variable concentrations, along with key forcing functions and process rates for every segment at userspecified print intervals. Major processes and variables included in the EUTRO module, Fig. 4.

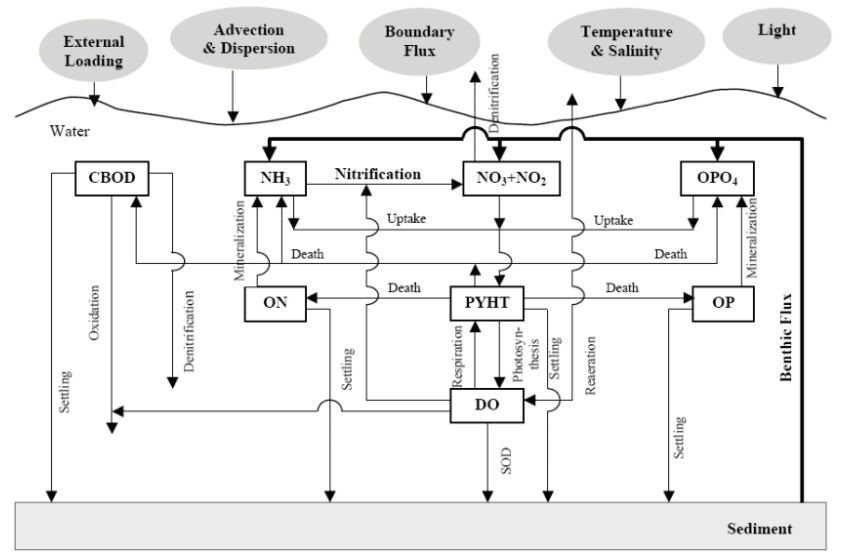

Fig. 4. Major processes and variables included in the EUTRO module [21].

\subsection{GEMSS}

Model GEMSS ${ }^{\circledR}$ (Generalized Environmental Modeling System for Surface waters) produced by Environmental Resources Management (ERM® Inc. Exton, PA, USA) [19] is a three-dimensional and multifunctional mathematical model designed to simulate the surface water environment (GEMSS ${ }_{\circledast}$ software). GEMSS, like WASP consist of different modules used for specific applications. The main modules of GEMSS ${ }^{\circledR}$ family are: hydrodynamic, sediment transport, differential thermal, chemical and oil spills, toxic spread, construction of wetlands, water quality. WASP's module EUTRO is directly used in GEMSS.

The basic principle of the water-quality models is based on the conservation of mass. The water volume and water-quality constituent masses being studied are tracked and accounted for over time and space using a series of mass balance equations assuming vertical and lateral homogeneity.

There are two main challenges deciding about accuracy of water quality models; correct determination of kinetics of nutrients cycle and correct hydrodynamics of water flow. The first challenge is satisfied by calibration technique to adapt kinetic model parameters to a particular water body by achieving the smallest discrepancies between simulation results and measurement data.

As an example, calibration principle on the basis of phytoplankton growth modeling is described below.

Phytoplankton growth kinetics assume a central role in prediction of the eutrophication process. Changes the amount of phytoplankton during the day in the particular segment is defined by the concentration of chlorophyll ,a" (mg/L/day). Quantity of phytoplankton in the water column depends on the growth and sedimentation rate as well as mortality. Phytoplankton concentration in the water body is described by the equation:

$$
\frac{\partial C_{p}}{\partial t}=\left(R_{G}-R_{D}-R_{S}\right) C_{p}
$$

where: $\mathrm{C}_{\mathrm{p}}$ - phytoplankton concentration $(\mathrm{mg} / \mathrm{L}), \mathrm{R}_{\mathrm{G}}$ growth rate constant $\left(\right.$ day $\left.^{-1}\right), \mathrm{R}_{\mathrm{D}}$ - death rate constant $\left(\right.$ day $\left.^{-1}\right), \mathrm{R}_{\mathrm{S}}$ - settling rate constant $\left(\right.$ day $\left.^{-1}\right)$.

The specific growth rate $R_{G}$ is defined via the following equation:

$$
\mathrm{R}_{\mathrm{G}}=G_{\max } X_{T} X_{L} X_{N}
$$

where: $\mathrm{G}_{\max }$ - the maximum growth rate in $20^{\circ} \mathrm{C}$, at optimum light and nutrients conditions $\left(\right.$ day $\left.^{-1}\right), X_{T}$ - the temperature adjustment factor, dimensionless, $\mathrm{X}_{\mathrm{L}}$ - the light limitation factor (function of incident solar radiation (ly/day)), $X_{S}$ - the nutrient limitation factor as a function of dissolved inorganic phosphorus and nitrogen. The total biomass reduction rate $R_{D}$ for the phytoplankton in the segment due to the death rate is expressed by the equation:

$$
R_{D}=k_{1 R}(T)+k_{1 D}+k_{1 G} Z(t)
$$

$\mathrm{k}_{1 \mathrm{R}}=$ endogenous respiration rate constant, day ${ }^{-1}, \mathrm{k}_{1 \mathrm{D}}=$ mortality rate constant, day ${ }^{-1}, \mathrm{k}_{1 \mathrm{G}}=$ grazing rate constant, day $^{-1}, \mathrm{Z}(\mathrm{t})=$ herbivorous zooplankton population grazing on phytoplankton, $\mathrm{mg} \mathrm{C} / \mathrm{L}$.

The settling of phytoplankton cells makes an important contribution to the overall mortality of the phytoplankton population, particularly in lakes, reservoirs and coastal oceanic waters. Sedimentation of phytoplankton is described by the relationship:

$$
R_{S}=\frac{v_{S} A_{S}}{V}
$$

where: $v_{S}=$ settling velocity, $\mathrm{m} /$ day, $A_{S}=$ surface area, $\mathrm{m}^{2}, V=$ segment volume, $\mathrm{m}^{3}$. 
Table 1 shows the variables and parameters in the net phytoplankton growth equations. In the second column an average range of constants in kinetics equations for phytoplankton growth is displayed.

Table 1. Phytoplankton Growth Terms (WASP).

\begin{tabular}{|l|l|l|}
\hline Description & $\begin{array}{c}\text { Average } \\
\text { range }\end{array}$ & $\begin{array}{c}\text { Sulejow } \\
\text { Reservoir }\end{array}$ \\
\hline Light extinction coefficient & $0,1-5$ & $1, \mathrm{~m}^{-1}$ \\
\hline Segment depth & $0,1-30$ & $0,3-7, \mathrm{~m}$ \\
\hline Water temperature & $0-35$ & $0-25, \mathrm{oC}$ \\
\hline $\begin{array}{l}\text { Fraction of day that is } \\
\text { daylight }\end{array}$ & $0,3-0,7$ & $0,3-$ \\
\hline $\begin{array}{l}\text { Average Daily Surface } \\
\text { Solar Radiation }\end{array}$ & $200-750$ & $500 \mathrm{Ly} / \mathrm{day}$ \\
\hline $\begin{array}{l}\text { Zooplankton Population - } \\
\text { Rate Constants }\end{array}$ & $0-1$ & $0,5 \mathrm{mg} \mathrm{C} / 1$ \\
\hline $\begin{array}{l}\text { Endogenous Respiration } \\
\text { Rate at 20 }{ }^{\circ} \mathrm{C}\end{array}$ & 0,05 & 0,05 \\
\hline Settling Velocity & $0,01-0,2$ & 0,15 \\
\hline Death Rate & $0-0,25$ & 0,05 \\
\hline Grazing Rate & $0-5$ & 1,5 \\
\hline
\end{tabular}

In the next step, in all water quality models, specific value of constant for a given water body should be determined. This step is called calibration of the model; the constants are determined by trial and error method using experimental data for analyzed water body.

Selected constants for phytoplankton kinetics calculated by WASP for the Sulejow Reservoir are presented in Table 1. Such an approach gives reliable and exact values of the simulated parameters of the eutrophication process assuming high quality and sufficient quantity of the data.

Similar approach is applied for phosphorus cycle, nitrogen cycle and oxygen balance. An example of GEMSS simulations (both validation and calibration) for water temperature and nitrates concentration in the Sulejow Reservoir is shown in Fig. 5 and 6.

a)

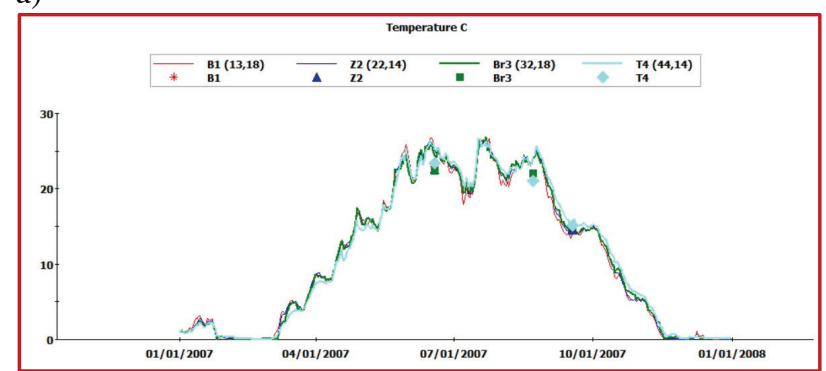

b)

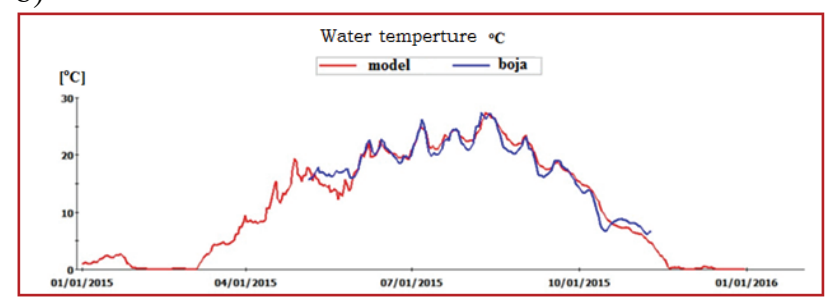

Fig. 5. a) Water temperature in Sulejow Reservoir in 2007 model calibration b) Water temperature in Sulejow Reservoir in 2007 - model verification.

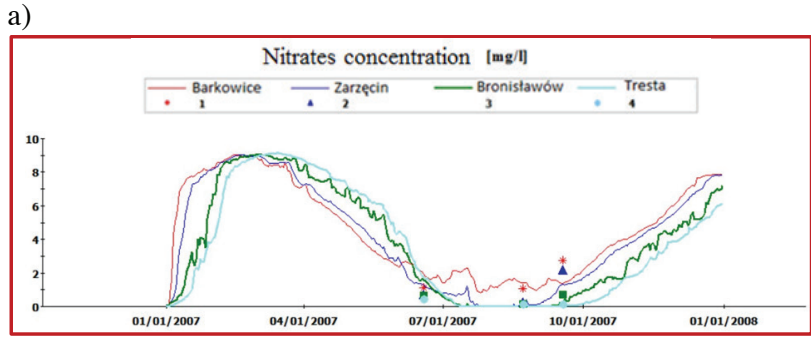

b)

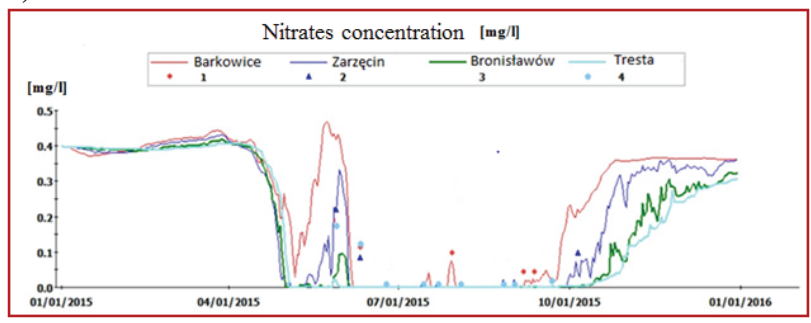

Fig. 6. a) Nitrates concentration in the Sulejow Reservoir in 2007 - model calibration b) Nitrates concentration in the Sulejow Reservoir in 2015 - model validation.

GEMSS model for the Reservoir was calibrated using data from 2007 [22]; good match of theoretical calculations with experimental measurements for prediction of both parameters in 2015 proves accuracy and versatility of GEMSS methodology. [23].

On the bases of calibrated water quality model scenarios for improving the ecological potential of the Reservoir can be determined, Fig. 7.

Analysis of Fig. 7 shows that $50 \%$ reduction of nutrients input results in threefold concentration of nitrogen in the lake.

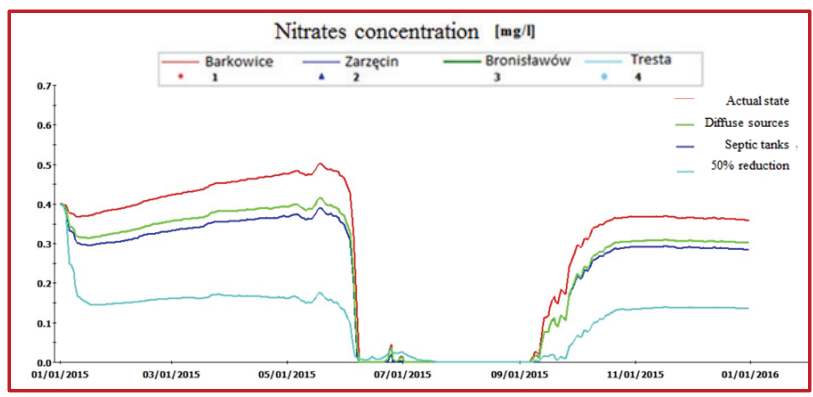

Fig. 7. Scenarios for improving the ecological potential of the Reservoir.

The results of simulations might help decision maker to undertake actions to reduce inflow of nutrients to obtain significant reduction of concentration of biogenic substances in the lake.

\section{Effect of hydrodynamics on nutrients distribution}

There is a number of literature suggestions that essential factor affecting phytoplankton community structure and cyanobacteria appearance is the hydrodynamics in the lake [13, 24, 25, 26, 27].

All water quality models contain hydrodynamic modules but owing to large size and complexity of the computational grid, none of existing water quality 
models can deliver reliable picture of hydrodynamics in a big water bodies. Important issue is how simplified hydrodynamics might affect final predictions of nutrient flow in the large water reservoirs.

For accurate determination of hydrodynamics Computational Fluid Dynamics (CFD) technique is commonly used. CFD technique is complex, requires experience and knowledge in elaboration of geometry of the object, optimization of numerical grid, selection of proper turbulence model (for big water bodies flow is turbulent because of the low water viscosity and large transverse dimensions) and, always verification of calculated flow patterns with experimental data [27].

Additionally, especially for shallow, polymictic lake, the impact of wind might be important for the distribution and mixing of the water masses.

In Fig. 8 results of CFD calculations (Ansys Fluent 14.0) for 17th-kilometer long Sulejow Reservoir show strong effect of wind on surface streamlines [17]. Significant differences in the course of the path lines and velocity fields are noticeable when the effect of the wind is considered. The simulations show, that when steady flow pattern develops in the basin, a large recirculation zones are formed bellow the outlet of the reservoir.

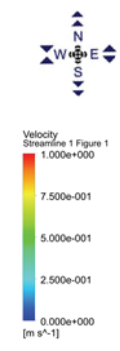

No wind conditions
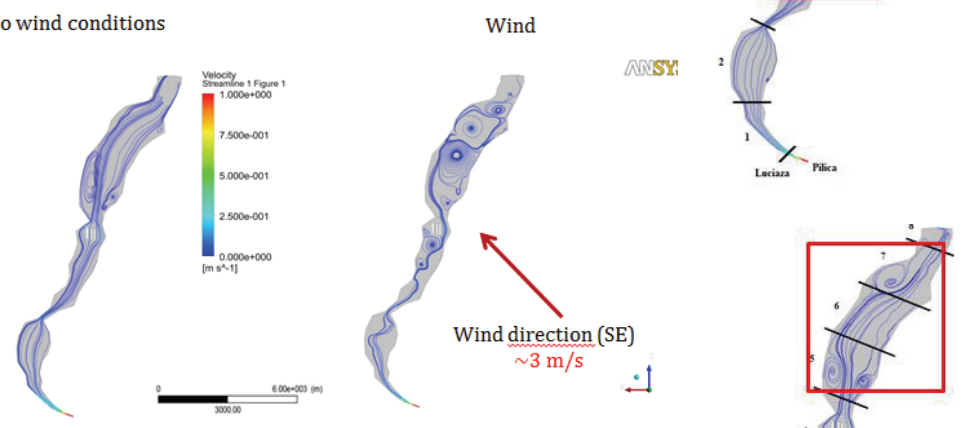

of the reservoir. The length and color of the vectors depict the magnitude of the velocity, as well as the direction of flow. Such circulating structures, reached the size of even half kilometer and increase the water retention time. Results of CFD simulations were verified by field measurements in selected cross-sections of the lake [17].

Recirculation zones have also a clear impact on the distribution of phytoplankton cells during the water blooms. Lacustrine area of the reservoir is characterized by significant slowing the flow $<0,1 \mathrm{~m} / \mathrm{s}$, which develops favorable conditions for the growing of algae species.

Hydrodynamics obtained from CFD calculations cannot be directly used in water quality models. Manual transfer of data, however, is possible which increase accuracy of determination of nutrients concentrations in the lake. Fig. 10 shows comparison of chlorophyll ,a” concentrations during the vegetation season, combined with the hydrodynamic conditions.
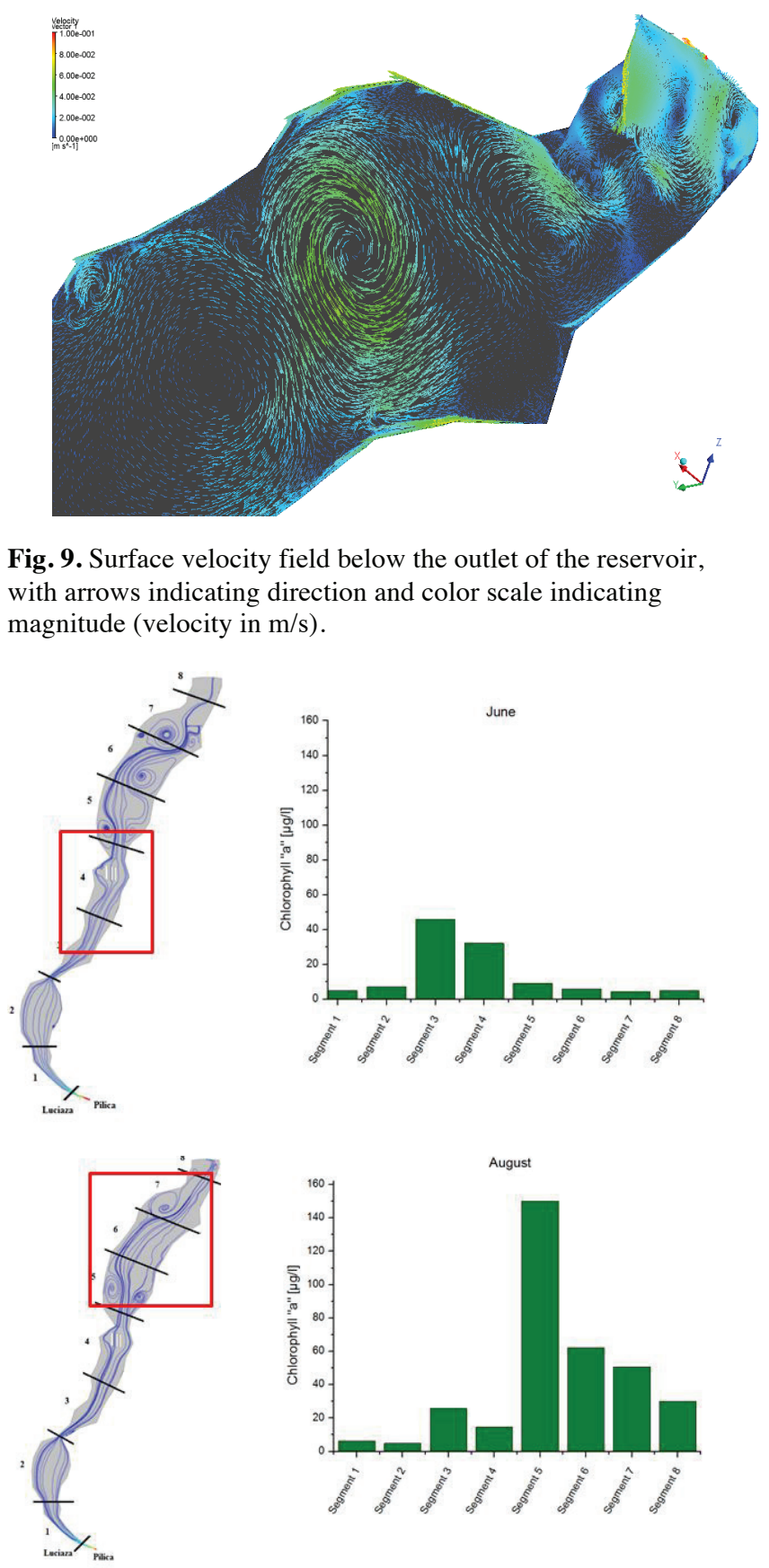

Fig. 9. Surface velocity field below the outlet of the reservoir, with arrows indicating direction and color scale indicating magnitude (velocity in $\mathrm{m} / \mathrm{s}$ ).
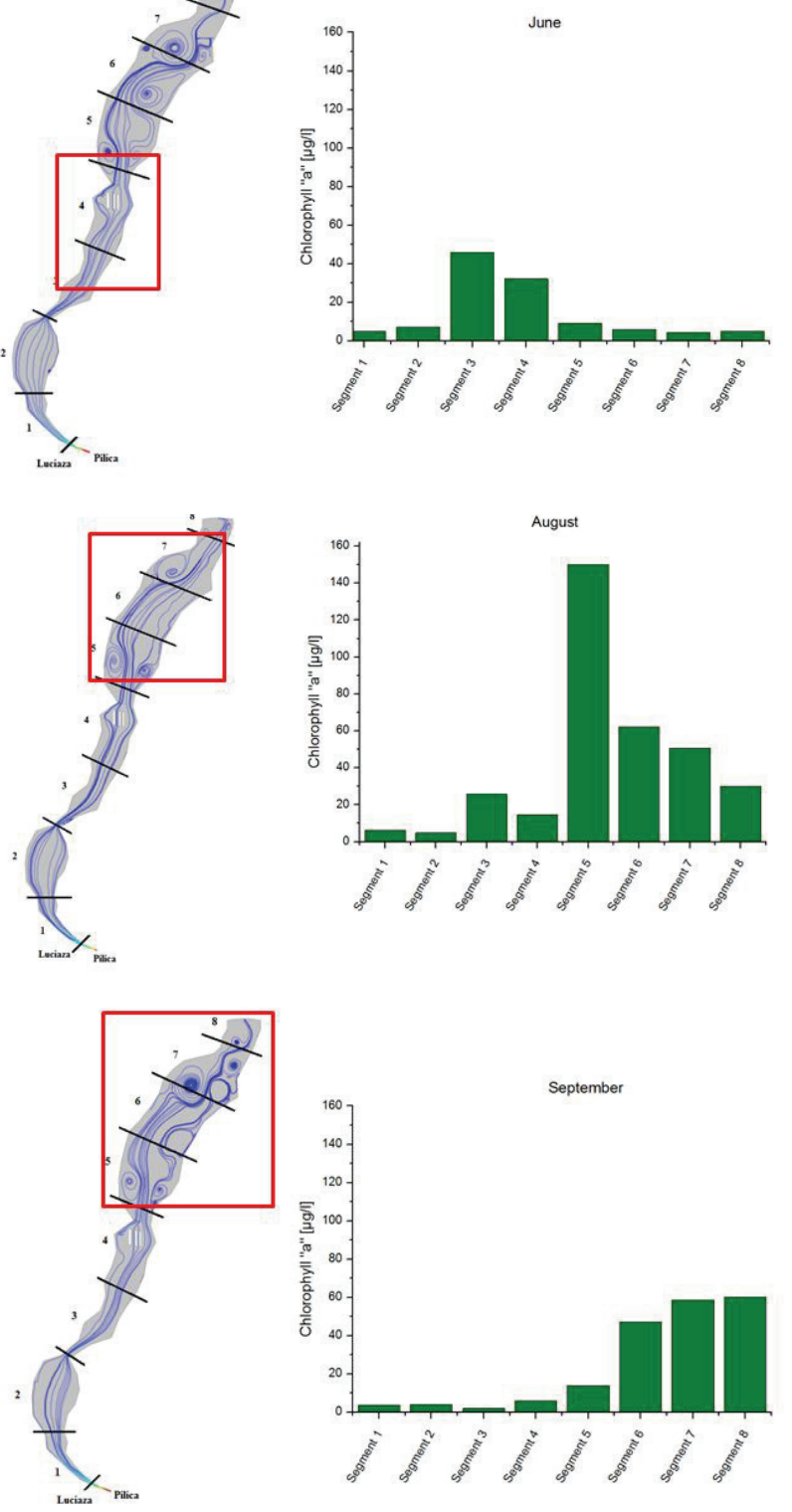

Fig. 10. Comparison of chlorophyll ,a" concentrations during the vegetation season, combined with the hydrodynamic conditions. Red squares present areas with the highest concentration of the analyzed parameter. 
Analysis of the results shows the movement of plankton biomass from segments 2, 3 and 4 in June to segments 6 , 7 and 8 in August and September. Results of simulations show that chlorophyll "a" content is strongly affected by hydrodynamics; in the recirculation zones higher concentrations of the parameter are due to higher retention time [28,29].

Analysis of Fig. 10 shows that accurate chlorophyll "a" concentration can not be obtain without determination of hydrodynamics in large water bodies.

Grid with 17 million elements was necessary to predict correctly hydrodynamics in Sulejow Reservoir whereas typical Hydrodynamic Module in water quality models (WASP, GEMSS, etc.) offers space for about 60000 numerical cells (around 300 times less than in CFD model) only which introduce large element of uncertainty in calculations of hydrodynamic and further in determination of nutrients flow in the large lakes.

Identification of mechanisms which control water quality in dam reservoirs is a scientific basis for undertaking practical actions, whose aim can be both to retain the status of the aquatic environment and also to improve it in the defined time horizon, depending on changing anthropogenic pressure on the natural environment.

\section{Conclusions}

State monitoring of water quality is rare and delivers sparse data which might not be representative for the large water body.

The application of mathematical modelling to water quality has proved to be a powerful support in water resources management. As a predictive tool, mathematical model allows forecasting and evaluation of effects of changes in the surrounding environment on the ecological status of the analyzed water bodies. As a diagnostic tool, permits a description of highly complex, real conditions. WASP model was used to determine the water quality in the Sulejow Reservoir and GEMSS model was used to determine the percent reduction in discharges derived from supplying rivers, necessary to improve the water quality standard in the Sulejow Reservoir.

One of the most important challenge controlling accuracy of water quality models is satisfied by calibration technique to adapt kinetics model parameters to a particular water body by achieving the smallest discrepancies between simulation results and measurement data. Such an approach can give a reliable description of the eutrophication process assuming high quality and sufficient quantity of the measured data.

The methodology of mobile monitoring measurements of water quality parameters which is compliant with the standards used in surface water monitoring studies developed in a frame of MONSUL project may deliver large number of high quality data.

Hydrodynamic characteristics, such as residence time, surface circulation pattern and turbulent mixing are affecting quality of surface water bodies. In order to predict areas of algal blooms, the hydrodynamics should be correlated with the nutrient kinetics growth.

Application of calibrated and verified water quality models, can be used to identify mechanisms controlling water quality and to elaborate control strategies and scenarios for improving the ecological potential of water body with reduced cost of monitoring.

\section{References}

1. http://www.gios.gov.pl/pl/stan-srodowiska/pms (accessed August 05. 2017)

2. www.monsul.wipos.p.lodz.pl (accessed August 05 . 2017)

3. H.B. Glasgow, J.M. Burkholder, R.E. Reed, A.J. Lewitus, J.E. Kleinmann, J. Exp. Mar. Biol. Ecol. 300, (2004)

4. Q. Wang, S. Li, P. Pia, Ch.Qi, F. Ding, Sci World J, 231768, 7 (2013)

5. Z.X. Xu, S.Q. Lu, J Hydrodyn. 15, 2 (2003)

6. S.E. Jorgensen, Lake Reserv Manage J. 3 (2001)

7. D.M. Di Toro, J.P. Connolly, Mathematical Models of Water Quality in Large Lakes, (USEPA, 1980)

8. R. V. Thomann, J.A. Muller, Principles of surface water quality modeling and control, (Harper \& Row Publishers, 1987)

9. W.S Lung, Water quality modeling for waste load allocations and TMDLs, (John Wiley \& Sons Inc., 2001)

10. G.T. Orlob, Mathematical Modeling of Water Quality: Streams, Lakes, and Reservoirs (John Willey \& Sons, 1983)

11. J.L. Martin, S.C. McCutcheon, Hydrodynamics and transport for water quality modeling (CRC Press, Inc., 1999)

12. S.D. Lau, V.R. Stovin, I. Guymer, Water Sci. Technol. 55, 4 (2007)

13. R. Pastres, S. Ciavatta, Environ. Modell Softw. 20, 8 (2005)

14. X.J. Cao, H. Zang, J. Water Resour. Archit. Eng. 4, 4 (2006)

15. D.J. O'Connor, Water Resour Res, 3, (1967)

16. D.M. Di Toro, J.J. Fitzpatrick, R.V. Thomann, Water Quality Analysis Simulation Program (WASP) and Model Verification Program (MVP) Documentation, (Hydroscience Inc., Westwood, NY, 1983).

17. A. Zieminska-Stolarska, Analysis of the flux of biogenic substances on water eutrophication in the large water bodies on the example of the Sulejow Reservoir, $\mathrm{PhD}$ Thesis, Lodz University of Technology, (2014)

18. R. Miranda, F. Braunschweig, P. Leitão, R. Neves, F. Martins, A. Santos, Ecol. Environ 40 (2000)

19. GEMSS ${ }^{\circledR}$ Workshop Guide, ERM Inc., (Exton, PA, USA, 2009) 
20. Danish Hydraulic Institute, MIKE21: User Guide and Reference Manual (Danish Hydraulic Institute, Horsholm, 1996)

21. T.A. Wool, R.B. Ambrose, J.L. Martin, E.A. Comer, Water Quality Analysis Simulation Program (WASP) - version 6.0. USEPA, Atlanta, 2001)

22. Voivodeship Inspectorate For Environmental Protection in Lodz. Report on the state of water purity in the Sulejow Reservoir in 2007, (Lodz 2008)

23. B. Rakowska, M. Sitkowska, E. Szczepocka, B. Szulc, Oceanol. Hydrobiol. Stud. 1 (2005)

24. J. Kubrak, E. Nachlik, Hydraulic bases of flow capacity calculation for river beds, (SGGW, Warsaw, 2003)

25. V.A. Verkhozina, O.M. Kozhova, Y.S. Kusner, Aquat. Ecosyst. Health 3, 2 (2000)

26. Deus, R., Brito D., Kenov I.A., Lima M., Ecol. Modell. 253 (2013)

27. A.G. Andersson, P. Andreasson, T.S. Lundström, Eng. Appl. Comp. Fluid 7, 1 (2013)

28. K. Izydorczyk, M. Tarczynska, Ecohydrol. Hydrobiol. 5 (2005)

29. A.K.M. Kabzinski, H. Grabowska, Gospodarka Wodna, 5 (2008) 